\title{
Educação Patrimonial no Campo da Arqueologia: desafios e contribuições
}

\author{
Carlúcio Baima ${ }^{1}$ \\ carlucio.brito@iphan.gov.brou carluciobaima@gmail.com; \\ Fernanda Biondo ${ }^{2}$ \\ fernanda.biondo@iphan.gov.brou ferbiondo@gmail.com; \\ Mariana Kimie Nito $^{3}$ \\ mariana.nito@iphan.gov.brou marykn@gmail.com;
}

\section{RESUMO}

Este artigo abrangerá questões referentes a preservação do patrimônio cultural tendo como foco o papel da Educação Patrimonial nos trabalhos arqueológicos tratados durante o Mini Curso ministrados pelos autores na Segunda Semana de Arqueologia da UNICAMP. Apesar das exigências de Educação Patrimonial em licenciamentos ambientais, com pesquisas cada vez mais crescentes, não há diretrizes ou especificações que orientem estas ações, que podem ser elaboradas de formas variadas. $\mathrm{Na}$ atual conjuntura, vemos que a Educação

\footnotetext{
${ }^{1}$ Licenciado em História pela Universidade Estadual do Maranhão - UEMA (2013). Atualmente é bolsista do Mestrado Profissional em Preservação do Patrimônio Cultural do Instituto do Patrimônio Histórico e Artístico Nacional - IPHAN, lotado no Centro Nacional de Arqueologia (CNA), tendo como objeto de pesquisa a Educação Patrimonial desenvolvida nos projetos de Arqueologia. Tem experiência profissional como monitor e bolsista pela Fundação de Amparo à Pesquisa no Maranhão (FAPEMA), no Centro de Pesquisa de História Natural e Arqueologia do Maranhão e lecionou a disciplina de História na rede particular de ensino. Desenvolve pesquisas no âmbito da História das Ciências da Saúde. Integrou equipes de Educação Patrimonial em projetos de Arqueologia de Contrato.

2 Bacharel e licenciada em História pela Universidade Estadual de Campinas - UNICAMP (2011). Atualmente é bolsista do Mestrado Profissional em Preservação do Patrimônio Cultural do IPHAN, lotada na Superintendência de Pernambuco, cujo tema de pesquisa e atividades práticas na Superintendência é a Educação Patrimonial, onde já desenvolveu diversas ações. Possui experiência profissional como Coordenadora do Departamento de Pesquisas da Associação Pró Memória de Sumaré, onde organizou o I e II Fórum de Patrimônio e Memória de Sumaré $(2013,2014)$ e a $1^{\underline{a}}$ e $2^{\underline{a}}$ edições da Revista Pró-Memória (2014 e 2015; ISSN 2359-1013). Membro conselheira do CONDEPHAEA (Conselho de Defesa do Patrimônio Histórico, Artístico, Etnológico e Ambiental de Sumaré). Docência para o Ensino Fundamental.

${ }^{3}$ Arquiteta e Urbanista graduada pela Escola da Cidade- AEC-SP (2012). Especialista em Gestão de Restauro e Prática de Obras de Conservação e Restauro do Patrimônio Cultural pelo Centro de Estudos Avançados da Conservação Integrada - $\mathrm{CECl}$, do Departamento de Arquitetura e Urbanismo da Universidade Federal de Pernambuco - UFPE (2014). Atualmente é bolsista do Mestrado Profissional em Preservação do Patrimônio Cultural (PEP/MP) do IPHAN, lotada na Superintendência de São Paulo, onde desenvolve pesquisa sobre área de entorno dos bens tombados com ênfase na análise da cidade como artefato cultural. Tem experiência na área de planejamento urbano e preservação. Organizou o Seminário Regional de Ensino da Federação Nacional dos Estudantes de Arquitetura e Urbanismo em 2010 que teve como diretriz a educação como ferramenta de transformação social. E participa da Rede Paulista de Educação Patrimonial- REPEP.
} 
Patrimonial não deve se limitar a atividades pontuais ou promocionais aos empreendimentos, mas, sobretudo, fomentar a construção coletiva do conhecimento e a autonomia dos sujeitos. Assim, neste artigo iremos elaborar uma análise sobre os desafios da Educação Patrimonial nas ações de licenciamento arqueológico, contribuindo para novas práticas educativas encaradas como ações político-sociais. E como tais assuntos foram tratados durante o Mini Curso.

Palavras chave: Arqueologia; Licenciamento Ambiental; Educação Patrimonial; Transdisciplinaridade; Patrimônio Cultural.

\begin{abstract}
This paper will cover issues related to preservation of cultural heritage focusing on the role of heritage education in archaeological work treated during the Course taught by the authors in Second Week of Archaeology at UNICAMP. Despite the demands of heritage education in environmental licensing, with ever-increasing research, there are no guidelines or specifications that guide these actions, which can be prepared in various forms. Currently, heritage education should not be limited to individual or promotional activities to enterprises, but, above all, to fostering the collective construction of knowledge and the autonomy of individuals. In this paper we will prepare an analysis on the challenges of heritage education in archaeological licensing actions, contributing to new educational practices seen as political and social actions. And as such matters were discussed at the Mini Course.
\end{abstract}

Keywords: Archaeology; Environmental Licensing; Heritage Education; Transdisciplinarity; Cultural Heritage.

\title{
RESUMEN
}

Este artículo cubrirá temas relacionados con la conservación del patrimonio cultural centrándose en el papel de la educación patrimonial en trabajos arqueológicos tratados durante el mini curso enseñado por los autores en la Segunda Semana de Arqueología en la UNICAMP. A pesar de las demandas de la educación del patrimonio en las licencias ambientales, con investigaciones cada vez más crecientes, no hay pautas o especificaciones para orientar estas acciones, que se pueden elaborar de diversas formas. En la situación actual, vemos que la educación sobre el patrimonio no debe limitarse a actividades individuales o de promoción para las empresas, sin embargo debe fomentar la construcción colectiva del conocimiento y la autonomía personal. Así que en este artículo vamos a realizar un análisis sobre los retos de la educación patrimonial en acciones de licencias arqueológicas, contribuyendo a nuevas prácticas educativas observadas como las acciones políticas y sociales. Y como tales asuntos se trataron durante el Mini Curso.

Palabras clave: Arqueología; Licenciamiento Ambiental; Educación Patrimonial; La transdisciplinariedad; Patrimonio Cultural.

\section{INTRODUÇÃO}

\begin{tabular}{|l|l|l|l|l|l|l|}
\hline (C) Rev. Arqueologia Pública & Campinas, SP & v.9 & No.s(11) & p.1-11 & suplemento & ISSN 2237-8294
\end{tabular}


Em linhas gerais, as pesquisas arqueológicas ganharam mais visibilidade ao longo do século XIX. No entanto, foi no século XX que ela foi consolidando seu arcabouço teórico e metodológico, bem como ampliando seu espaço de atuação, sendo reconhecido perante outras disciplinas. Inicialmente, o conhecimento produzido por aqueles que faziam arqueologia era de caráter elitista e de cunho nacionalista (havia uma preocupação na busca das origens), porém com o passar do tempo e, com o amadurecimento do seu campo disciplinar, a arqueologia se enveredou a compreender outras dinâmicas sociais, bem como de se aproximar da sociedade e de como esta percebe, entende e participa da produção do conhecimento acerca dos vestígios arqueológicos.

O patrimônio arqueológico passou a fazer parte da agenda dos estudos de impacto ambiental, principalmente, a partir da Resolução CONAMA n 001 , de 23 de janeiro de 1986 . O Instituto do Patrimônio Histórico e Artístico Nacional (IPHAN), no ano de 2002, publicou a Portaria no 230, que compatibiliza as etapas do licenciamento as fases da pesquisa arqueológica. Sem sombra de dúvidas, a maioria das pesquisas arqueológicas desenvolvidas atualmente no Brasil estão vinculadas ao Licenciamento Ambiental. A chamada "Arqueologia de Contrato", conhecida dessa forma em função da prestação do serviço de pesquisa arqueológica em uma área que será impactada por um determinado empreendimento, passou também a incorporar o campo da Educação Patrimonial.

Atualmente, os desafios para a elaboração e execução de Programas de Educação Patrimonial são diversos. Quando tais programas são colocados em prática no bojo do Licenciamento, as dificuldades tendem a ser maiores, como por exemplo, o tempo curto para planejar e executar os programas.

Dessa forma, procuramos com o minicurso apresentado na II Semana de Arqueologia, organizado entre os dias 23 e 27 de março de 2015, pelo Laboratório de Arqueologia Pública da Universidade Estadual de Campinas (UNICAMP), apresentar questões, discutir desafios e exemplos (expostos inclusive pelos participantes) no que diz respeito a Educação Patrimonial no campo da Arqueologia, aproximando sempre que possível, as outras dimensões do patrimônio cultural.

O artigo em destaque tem como proposta, além de relatar o desenvolvimento e experiência do minicurso, abordar conceitos e legislações que versam sobre o patrimônio arqueológico, brevemente contextualizar a trajetória da educação no campo da preservação e discutir os 
atuais princípios e diretrizes que norteiam a prática educativa na preservação do patrimônio cultural.

\section{Os desafios no desenvolvimento de Projetos de Educação Patrimonial na Arqueologia}

Na semana em que foi desenvolvido o minicurso, duas legislações entraram em vigência: a Portaria Interministerial $n^{\circ} 60$, de 24 de março de 2015 e a Instrução Normativa no 001, de 25 de março de 2015. Além de possuírem um espaço destinado aos Projetos de Educação Patrimonial, ambas substituíram respectivamente a Portaria Interministerial $n^{\circ} 419$, de 26 de outubro de 2011 e a Portaria IPHAN n²30, de 17 de dezembro de 2002. Citaremos no artigo apenas a Instrução Normativa, visto que a mesma possui um capítulo dedicado especialmente a Educação Patrimonial.

A Instrução Normativa procura minimamente corrigir alguns problemas teóricos e metodológicos no que tange a elaboração e execução de Projetos de Educação Patrimonial. Em relação às novas exigências, há um significativo avanço quanto ao que o IPHAN não irá mais aceitar enquanto Educação Patrimonial. Normalmente, uma grande parcela dos projetos restringiam (e restringem) suas ações a meras apresentações de informações e/ou instruções quanto ao patrimônio cultural, tendo como principais recursos na elaboração dos projetos folders, cartilhas e palestras.

Não há problemas na utilização destes recursos, assim como não há problemas em apresentar informações. Contudo, elas não suficientes para caracterizar um Projeto de Educação Patrimonial que necessitam de uma concepção, metodologia, justificativa, público, cronograma e objetivo. É importante que a equipe responsável pelos Projetos de Educação Patrimonial atente as características de cada contexto sociocultural, procurando identificar as especificidades dos públicos alvos que irão participar das atividades, de modo que haja uma participação ativa destes não apenas na sua execução, mas também na sua concepção e elaboração.

Sem sombra de dúvidas, os desafios para a elaboração de Projetos de Educação Patrimonial, no bojo do licenciamento ambiental são diversos, por exemplo, curto período para a realização das atividades; ampliar o público participante das ações, já que normalmente há uma predileção pelo público escolar; atentar as particularidades de cada contexto e reanalisar o período de execução dos projetos, quando couber, em função das realidades locais, e; 
programar uma vasta e exaustiva etapa de conhecimento das comunidades envolvidas e das suas referências culturais.

O tópico seguinte tem como intuito subsidiar estratégias para a elaboração desses projetos, tendo como base princípios e diretrizes conceituais largamente discutidos por profissionais do campo do patrimônio e que são, atualmente, uteis e indispensáveis quando se fala em Educação Patrimonial.

\section{Educação Patrimonial: princípios norteadores}

A concepção de que a educação pode ser um forte aliado no campo da preservação do patrimônio cultural não é recente. Desde a década de 1930, quando este campo foi institucionalizado no Brasil por meio da criação do Sphan (Serviço do Patrimônio Histórico e Artístico Nacional), acreditava-se na perspectiva de que a destruição dos monumentos nacionais poderia ser evitada a partir da educação popular, que deveria conhecê-lo e valorizálo. Esta concepção de educação foi sendo modificada, vista e revista ao longo das décadas. A oficialização do termo Educação Patrimonial ocorre em 1983, em meio ao contexto de debates nacionais e internacionais sobre o papel educativo dos museus ${ }^{4}$. Entendida como "um processo permanente e sistemático de trabalho educacional centrado no Patrimônio Cultural como fonte primária de conhecimento e enriquecimento individual e coletivo" (HORTA, et al, 1999, p. 06), apresentava uma proposta metodológica para estimular o desenvolvimento de ações educacionais voltadas para o uso e a apropriação das referências culturais que compõem o patrimônio cultural, envolvendo quatro etapas progressivas de conhecimento: observação, registro, exploração e apropriação.

Ao longo da década de 2000, o tema Educação Patrimonial foi muito debatido a nível nacional, por profissionais de diversas áreas, analisando, revisando e construindo novos conceitos, princípios norteadores e percepções sobre esta temática. Assim, em 2011, no II Encontro Nacional de Educação Patrimonial, chegou-se ao conceito atual que propõe um movimento diferente de aproximação das comunidades, considerando que

Educação Patrimonial constitui-se em todos os processos educativos, formais e não formais que tem como foco o Patrimônio Cultural, apropriado

\footnotetext{
${ }^{4}$ I Seminário sobre o Uso Educacional de Museus e Monumentos, realizado no Museu Imperial de Petrópolis-RJ. Vale ressaltar que atividades educativas para valorização do patrimônio já ocorriam no âmbito dos museus e do Iphan anteriormente à esta oficialização do termo - e da prática - em 1983.
} 
socialmente como recurso para a compreensão sócio-histórica das referências culturais em todas as suas manifestações, a fim de colaborar para seu reconhecimento, sua valorização e preservação. Considera, ainda, que os processos educativos devem primar pela construção coletiva e democrática do conhecimento, por meio do diálogo permanente entre os agentes culturais e pela participação efetiva das comunidades detentoras e produtoras das referências culturais, onde convivem diversas noções de Patrimônio (IPHAN, 2014, p. 19).

As discussões atuais sobre Educação Patrimonial também fomentaram a elaboração de princípios norteadores que podem colaborar para a construção de projetos educativos e para uma maior reflexão desta temática ${ }^{5}$ :

1) Transversalidade: Quando a Educação Patrimonial é encarada como um componente essencial de todo o processo de valorização e preservação, possibilita a construção coletiva do conhecimento, a partir do diálogo e da negociação. No entanto, quando as atividades educativas são pensadas apenas como produtos finais dos processos de preservação, configura-se seu caráter informativo, de transmissão do conhecimento técnico. Assim, a Educação Patrimonial deve permear às demais ações patrimoniais (inventariação, diagnóstico, tombamento, registro, conservação, restauro, celebração) e, no caso da Arqueologia, deve transpassar as etapas de pesquisa, evitando-se desenvolvê-la apenas ao final do processo.

2) Campo de disputa e conflitos: O campo do patrimônio cultural é uma arena de conflitos diversos, marcado por disputas constantes pela construção de significados e narrativas sobre objetos e práticas sociais. É importante reconhecer essa dimensão política das práticas preservacionistas em sua relação com os diferentes segmentos, setores e grupos sociais envolvidos por meio de uma atuação dialógica e de troca constante.

3) Diálogo - Mediação: o papel das instituições de preservação em relação à sociedade civil, "mais do que propriamente determinar valores", é de mediação, criando espaços de aprendizagem e interação para fomentar a reflexão dos grupos sociais em relação ao seu próprio patrimônio. As ações educativas devem, neste sentido, ser emancipatórias, ouvindo e construindo junto, socializando o conhecimento técnico-científico e, ao mesmo tempo, valorizando os conhecimentos e práticas sociais. Dessa forma, a Educação Patrimonial deve partir de uma concepção de liberdade e autonomia dos sujeitos envolvidos, considerando que

${ }^{5}$ Expomos aqui alguns princípios e diretrizes conceituais da Educação Patrimonial com base das premissas estabelecidas no II Encontro Nacional de Educação Patrimonial de 2011, na publicação do Iphan "Educação Patrimonial: histórico, conceitos e processos", e pela Rede Paulista de Educação Patrimonial. 
o desenvolvimento dos projetos educativos não tratem as comunidades simplesmente como receptoras das ações instituídas por especialistas, criados de cima para baixo, sem ouvir os principais interessados, sem conhecer o local e as pessoas (SCIFONI, 2012, p. 32).

4) Construção coletiva - respeito à diversidade: Reconhecer as diversidades socioculturais brasileiras é premissa fundamental para o desenvolvimento de ações de Educação Patrimonial. É dizer que os conhecimentos e saberes locais também devem ser considerados nos processos de preservação, "por meio de mecanismos de escuta e observação que permitam acolher e integrar as singularidades, identidades e diversidades locais" (FLORÊNCIO, 2012, p. 25). Essa perspectiva contribuiria para a "tomada de consciência dos homens como sujeitos da sua própria história" (SCIFONI, 2012, p. 33) e valorizaria seus contextos culturais, estimulando a ressignificação dos bens culturais (FLORÊNCIO, 2012, p. 25).

5) Interdisciplinaridade: o campo do patrimônio é, por excelência, um campo de atuação multidisciplinar. Assim, as práticas educativas não devem ser limitadas à atuação de profissionais da área da Educação, mas serem incorporadas pelos diferentes setores que compõem a ação. Antropólogos, historiadores, arqueólogos, arquitetos, biólogos, geólogos, entre outros podem, coletivamente com a comunidade, construir as ações de reconhecimento e valorização das referências culturais, contribuindo com olhares e perspectivas diversas.

6) Territórios como espaços educativos: "espaços educativos" não o são por natureza, mas "tornam-se a partir da apropriação que as pessoas fazem dele" (FARIA, 2010, p. 25), por meio de ações práticas, implicando numa nova concepção de educação, que extrapola os muros das escolas. O conceito de espaço/território educativo estaria, assim, relacionado ao de Educação Integral, salientando que as experiências educativas são mais efetivas quando integradas às demais dimensões do cotidiano das pessoas, construindo e reconstruindo significados. Desta forma, percebe-se uma concepção abrangente de Educação, em que "o processo educativo confunde-se com um processo amplo e uniforme de socialização" (FARIA, 2010, p. 18), de modo a propor que a educação deve ser pensada para além dos espaços de educação formal, considerando a cidade, o bairro e os bens culturais como potencialmente educadores (IPHAN, 2014, p. 33).

\section{O Mini Curso}


Durante a Segunda Semana de Arqueologia da Universidade Estadual de Campinas (UNICAMP) cuja temática foi "História e Cultura Material: desafios da contemporaneidade", foi ministrado pelos autores deste artigo o Mini Curso Educação Patrimonial no Campo da Arqueologia: desafios e contribuições que ocorreu nas manhãs dos dias 24 e 25 de março de 2015, totalizando 6 horas de duração. Contou em média com a participação de 18 participantes de diferentes localidades do Brasil e cuja maioria era estudantes universitários da graduação e mestrado.

O objetivo do Mini Curso foi refletir sobre a prática da Educação Patrimonial nos processos de reconhecimento, valorização e preservação do patrimônio cultural no licenciamento ambiental visando à potencialidade de ações de interlocução junto a comunidade diretamente envolvida. E, preocupados com o tempo de exposição teórica e com a produção de um registro do conteúdo aos participantes produzimos um material didático, intitulado Caderno de Memórias, que teve a finalidade de apresentar os tópicos tratados durante o Mini Curso e apresentar mais referências sobre a Educação Patrimonial e Arqueologia, a partir de uma bibliografia comentada e uma indicada por temáticas, com as obras consideradas fundamentais.

A primeira parte do Mini Curso contou com a introdução sobre patrimônio cultural e licenciamento ambiental. Em diversos momentos desta exposição teórica, os participantes fizeram contribuições significativas sobre suas experiências de atuação e as dificuldades encontradas em campo, e principalmente, em relação às atividades educativas que muitas vezes são desastrosas, como exemplo a distribuição de pirulitos para crianças. Ademais, no fervor das discussões, um dos participantes propôs um espaço do Mini Curso para a elaboração coletiva de uma Carta com reflexões sobre a problemática a ser encaminhada para instituições responsáveis pela salvaguarda do patrimônio arqueológico ${ }^{6}$.

Posteriormente, apresentamos alguns materiais, que levamos para consulta dos participantes, sobre ações educativas ${ }^{7}$ no campo do patrimônio. A exposição destes teve foco no processo em que foram executados, identificando os limites e possibilidades das ações, a fim de despertar o olhar dos participantes sobre as diferentes maneiras de comunicar e sensibilizar determinados públicos alvos. Tivemos, também, o cuidado de apresentar ações não somente

${ }^{6}$ Infelizmente, a redação da Carta de Reflexões não foi feita por falta de tempo. Os participantes sugeriram ao fim escrevê-la, posteriormente on-line.

7 O termo "ações educativas no campo do Patrimônio" foi aqui utilizado, pois nem todos os casos apresentadas são de fato reconhecidas como ações de Educação Patrimonial, como exemplos: cd do jongo no sudeste, revista do patrimônio e etc.

(C) Rev. Arqueologia Pública

\begin{tabular}{l|l|} 
Campinas, SP & v.9
\end{tabular}

No.s $(11)$ p.1-11 suplemento

ISSN 2237-8294 
voltadas a arqueologia, explorando outras dimensões que o patrimônio cultural abarca, como a relação com as cidades, lendas e tradições, entre outros que também podem ser articuladas nas etapas de licenciamento ambiental. Todo material circulou pelas mãos dos participantes para que eles pudessem manuseá-los e anotar referências.

Concluímos o primeiro dia com uma rápida abordagem sobre a educação dentro do campo do patrimônio cultural. No dia seguinte, retomamos o assunto e apresentamos as reflexões atuais sobre educação Patrimonial. Finalizamos a exposição teórica com uma discussão aberta sobre os desafios da educação patrimonial nos projetos de arqueologia, no qual os participantes puderam discutir e fazer perguntas relacionando os princípios apresentados às realidades encontradas nos trabalhos com a arqueologia.

Como atividade prática final, os participantes foram divididos em grupos para pensar e propor ações educativas por meio de algum estudo de caso proveniente da experiência pessoal de um dos integrantes do grupo. A atividade foi muito instigante e cada grupo, apresentou uma dinâmica própria e distinta dos demais grupos, alguns aproveitaram o momento para trocar experiências e tirar dúvidas sobre os campos de atuação e outros seguindo o roteiro de orientação para aplicar uma ação patrimonial problematizando os pontos e vendo as possibilidades de trabalho.

Realizamos também, uma breve avaliação do Mini Curso, na qual pedimos para que os participantes preenchessem gentilmente um formulário que elaboramos para termos um retorno das opiniões e pensamentos deles sobre o Mini Curso. Obtivemos 16 respostas no total. Quanto ao Mini Curso, aproximadamente $90 \%$ declararam estar satisfeitos sobre as expectativas que tinham em relação aos assuntos tratados neste. No campo para comentários abertos sobre o Mini Curso, fomos muito elogiados por criar espaços abertos ao diálogo e construção colaborativa, bem como pela ênfase constante sobre "caráter dialético, reciproco e democrático atrelado a educação patrimonial" (Participante 3$)^{8}$. Um dos participantes declarou: "Quanto às expectativas devido à temática - ainda sem diretrizes - foi um pouco frustrante não receber uma "receita" que era o esperado quando fiz o minicurso." (Participante 1). De fato enfatizamos que não existe um método único e ideal para tratar a educação patrimonial, por isso exploramos as principais diretrizes para a articulação e realização de uma

\footnotetext{
${ }^{8}$ Em respeito à identidade dos participantes optamos por ocultar seus nomes na reprodução do que foi escrito e também reproduzimos a grafia original.
} 
ação educativa. Também, foi sugerido o aumento da carga horária do Mini Curso para apresentarmos uma ação/intervenção do processo de execução de ações de educação patrimonial. O participante 9 escreveu: "O mini curso atendeu as expectativas devida a quebra de conceitos que eu tinha sobre Educação Patrimonial. Mostrou-me outra visão da Educação Patrimonial". Tal relato releva uma das intenções que tivemos ao propor o Mini Curso durante a Segunda Semana de Arqueologia.

Nas questões referentes aos ministrantes do Mini Curso, escolhemos duas para citar diretamente por resumirem bem os comentários escritos que recebemos:

O dialogo fluído permeado pelos conhecimentos e exemplos de cada um dos três não só somar à teoria apresentada como foi fundamental para a fixação das práticas e noções como trabalhar a EP no dia a dia da minha área (no caso Arqueologia). A cartilha produzida será de grande valia [...]. (Participante 5)

E também: "Achei importante que os instrutores citaram as vantagens e desvantagens da Instituição [IPHAN] que estão inseridos trazendo à tona a realidade e ressaltaram a importância da participação popular na construção do patrimônio." (Participante 10).

Relacionado ao desempenho individual dos participantes $80 \%$ consideram-se seguros quanto à apreensão do conteúdo e afirmam ter cumprido os compromissos estabelecidos no Mini Curso. Mesmo antes de olharmos os formulários de avaliação considerávamos o Mini Curso ter cumprido com êxito os propósitos que queríamos realizar, estas avaliações foram de grande valia para confirmarmos nossa expectativa e também visando ao contínuo aperfeiçoamento de cursos que podemos oferecer no futuro.

\section{Bibliografia}

BEZERRA, M. Arqueólogos e Comunidades Locais no Projeto de Educação Patrimonial. In: Najjar, R. (Org.). Arqueologia no Pelourinho. Brasília: IPHAN: Programa Monumenta, 2010, p. 167-184.

Coletânea de Leis sobre preservação do Patrimônio. - Rio de Janeiro: IPHAN, 2006.

FARIA, Ana Beatriz Goulart de. Cadernos Pedagógicos: territórios educativos para a educação integral - a reinvenção pedagógica dos espaços e tempos da escola e da cidade. Ministério da Educação (MEC): agosto, 2010.

FLORẾNCIO, Sônia R. R. Educação Patrimonial: um processo de mediação. In: TOLENTINO, Átila Bezerra (org.). Educação Patrimonial: reflexões e práticas. João Pessoa:

Superintendência do Iphan na Paraíba, 2012. 
HORTA, M. GRUNBERG, E. MONTEIRO, A. Guia Básico de Educação Patrimonial, Iphan, 1999.

SCIFONI, Simone. Educação e Patrimônio Cultural: reflexões sobre o tema. In: TOLENTINO, Átila Bezerra (org.). Educação Patrimonial: reflexões e práticas. João Pessoa: Superintendência do Iphan na Paraíba, 2012

IPHAN. Educação Patrimonial: histórico, conceitos e processos. Brasília: Instituto do Patrimônio Histórico e Artístico Nacional, 2014. Disponível em: <http://www.iphan.gov.br/baixaFcdAnexo.do?id=4240> Acesso em: 20 jul. de 2014. 